\title{
Paternalistic Leadership and Enterprise Management Innovation: a Moderated Meta Analysis
}

\author{
Bo Lin ${ }^{1, a}$ Siyuan Chen*2,b \\ ${ }^{1}$ Department of Economics and Management Dalian University Dalian, China \\ ${ }^{2}$ Department of Economics and Management Dalian University Dalian, China
}

\begin{abstract}
Leadership style is an important factor influencing enterprise management innovation. Paternalistic leadership is a typical leadership style in China, which has a significant impact on enterprise management innovation. Objective: This paper is to explore the relationship between paternalistic leadership and business management innovation, and analyze potential variables to investigate the source of their differences. Methods: This paper takes 74 empirical studies (157 effect values, total sample size 28335) as the object, using meta-analysis technology to study the relationship between the three leadership types of paternalistic leadership, benevolent leadership, moral leadership and authoritative leadership and multi-focus enterprise management innovation. Based on a multi-dimensional perspective, enterprise management innovation under paternalistic leadership can be divided into: innovation ability orientation and innovation behavior orientation. In the context of paternalistic leadership, it is unclear which level of innovation has a stronger tendency to implement enterprise management innovation. Results: The correlation between benevolent leadership, authoritarian leadership, moral leadership and overall management innovation is 0.377 , -0.158 and 0.319 ; the correlation between moral leadership, benevolent leadership, authoritarian leadership and capability oriented management innovation is $0.344,0.395$ and- 0.192 respectively; benevolent leadership has the strongest correlation with behavior and ability oriented management innovation. Conclusion: the relationship between eastern and Western paternalistic leadership and enterprise management innovation is influenced by cultural context and innovation level. Benevolent leadership and moral leadership have significant positive effects on enterprise management innovation, and authoritative leadership has significant negative effects on enterprise management innovation. To a large extent, cross-cultural situations (China, non-China) and levels of innovation (individuals, teams, organizations ) have a moderating effect on the relationship between them.
\end{abstract}

\section{Introduction}

In recent years, innovation management has always been a topic that domestic and foreign scholars and corporate managers have worked hard to solve. With the development of the ideological trend of "mass entrepreneurship and innovation" in the new era and the increasingly competitive market competition environment, most organizations have to seek an effective way of "innovation-driven development", innovation is the key to the survival and development of an organization. The organization should continuously improve its own innovation awareness and ability to respond to the increasingly challenges with more innovative results [1].Innovation is one of the fundamental factors influencing the development and increasing strength of enterprises. The leadership method is to improve and stimulate enterprise management innovation. Employee innovation is an important situational factor [2]. Paternalistic leadership originated from China's organizational environment, but its influence has been widespread in the organizations of various countries [3-4]. Among them, paternalistic leadership is an important influence on enterprise management innovation [5], making it one of the leadership styles that have attracted much attention from scholars. Paternalistic leadership is a combination of "broad" and "strict" leadership styles. There is still no clear definition of the influence mechanism between it and enterprise management innovation. So is there some connection between paternalistic leadership and enterprise management innovation?

\subsection{The Relationship Between Paternalistic Leadership and Business Management Innovation.}

Paternalistic leadership is a leadership style with Chinese local characteristics, which means that in the organizational context, leaders show absolute authority, parental kindness and moral example. At present, researchers' research on paternalistic leadership is mainly based on the ternary theoretical model, that is,

\footnotetext{
alinbo@dlu.edu.cn

b*cicichen1002@163.com
} 
paternalistic leadership is led by authoritarian leadership, benevolent leadership and moral leadership[6].The composition of the guiding style. Authoritarian leaders emphasize their absolute authority and require their subordinates to carry out orders and obey strict arrangements without any objection; benevolent leaders regard subordinates as family members and show comprehensive and continuous care for employees like their parents and relatives in their work and life; moral guidance is mainly reflected in the excellent personal ethics of leaders, who obtain subordinates by examples Employee's imitation and respect. Enterprise management innovation is an important component dimension of enterprise innovation. It not only includes the innovation of production and practice in the traditional sense, but also includes the innovation of management theory, which is conducive to the enterprise to face the fierce market environment and better achieve the enterprise development goals[7]. In the process of putting forward the problem of enterprise management innovation, the leader's leadership style and behavior characteristics will greatly affect the organization's judgment and identification of innovation programs and problems. In the decision-making stage of enterprise innovation management, managers will choose the scheme of enterprise innovation management according to the existing problems and organizational situation.

\subsection{The Regulatory Factors of Paternalistic Leadership and Enterprise Management Innovation.}

The subject is the sender and undertaker of practical activities. The main body of innovation is a person who participates in the whole process of innovation from beginning to end, has his own creative ideas, has the innovation will and innovation ability, and puts it into practice. According to the different contents of enterprise management innovation, it can be divided into theoretical innovation subject, technological innovation subject and system innovation subject. Different innovation subjects have different innovative contents and abilities in the process of innovation. Therefore, different levels of innovation subjects have different degrees of influence on the overall innovation of enterprise management [8-9]. Based on this, on the basis of statistical literature, this study divides the orientation of enterprise innovation into capability oriented and behavior oriented management innovation according to the multi focus method. Innovation level is divided into three levels: individual, team and organization. Figure 1 shows the theoretical model of this study.

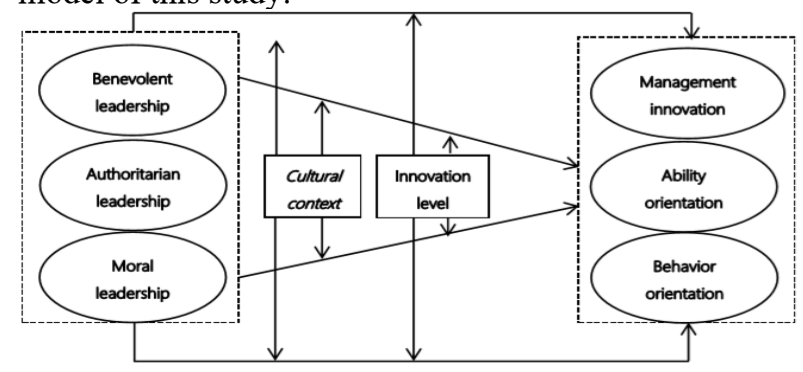

Fig 1. THEORETICA MODEL

\section{Research Method}

\subsection{Bibliography Retrieval}

we use various ways to collect empirical research literature on paternalistic leadership, benevolent leadership, moral leadership, authoritarian leadership and enterprise management innovation. First of all, search CNKI, Google Scholar and other commonly used Chinese and English databases. Finally, refer to the references of relevant articles to further supplement the literature.

\subsection{Literature Screening and Coding}

Finally, the literature included in the meta-analysis must meet the following criteria: (1) the research is an independent empirical study with the number of effect values no less than 1 ; (2) the antecedent variable of the study they are paternalistic leadership, and the result variable must reflect the enterprise innovation behavior effect values (28335 samples). The content of literature coding includes two aspects: sample characteristics and effect value. The sample characteristics include the author's name, sample number, cross-cultural context (China, non -China), innovation level (individual, team, organization) etc.

In order to ensure the accuracy of coding, two authors have coded this paper twice, and the consistency is more than $98 \%$.

\subsection{Analytical Technology}

In this study, CMA2.0 (Comprehensive meta-analysis) software was used for data processing. The specific analysis process is as follows: firstly, the correlation coefficient is used as the effect value statistic, and then the effect value of each independent sample is combined into an effect value by correlation coefficient. Secondly, the model was selected according to $\mathrm{Q}$ statistic and $\mathrm{I}^{2}$ index. Finally, the main effect analysis and regulation effect analysis are carried out in turn.

\section{RESULTS}

\subsection{Heterogeneity and Publication Bias Test}

Generally, in order to eliminate the sampling error of samples, it is necessary to test the heterogeneity of within group Q statistic with $\mathrm{I}^{2}$ index for different sample results [10].The results are shown in Table 1. In the research of enterprise innovation, the $\mathrm{Q}$ statistic is significant at the level of 0.001 , which indicates that the effect quantity of each research is heterogeneous, and the random model analysis method should be adopted. The value of $\mathrm{I}^{2}$ was 95.60 , which indicated that $95.60 \%$ of the observed variation came from the real difference, and the random error could only explain $4.40 \%$ of the observed variation. The value of $\mathrm{Tau}^{2}$ is 0.06 , which indicates that $6 \%$ of the variance among studies can be used to calculate the weight. 
The analysis of capability oriented and behavior oriented management innovation is the same as above.

Table1.

TEST RESULTS OF EFFECT HETEROGENEITY

\begin{tabular}{|c|c|c|c|c|c|c|c|}
\hline $\begin{array}{c}\text { Antecedent } \\
\text { variable }\end{array}$ & $\begin{array}{c}\text { Outcome } \\
\text { variable }\end{array}$ & $\mathbf{K}$ & $\mathbf{Q}$ & df & $\mathbf{I}^{2}$ & $\mathbf{T a u}^{2}$ & fail-safe $N$ \\
\hline Benevolent & $\begin{array}{c}\text { management } \\
\text { innovation }\end{array}$ & 47 & $1194.8^{* * *}$ & 49 & 95.60 & 0.06 & 54.1 \\
\hline \multirow[t]{2}{*}{ Leadership } & \multirow{2}{*}{$\begin{array}{c}\text { ability orientation } \\
\text { behavior } \\
\text { orientation }\end{array}$} & 31 & $968.72^{* * *}$ & 31 & 96.80 & 0.09 & 44.1 \\
\hline & & 18 & $222.3^{* * *}$ & 17 & 92.36 & 0.03 & 31.3 \\
\hline \multirow{3}{*}{$\begin{array}{c}\text { Authoritarian } \\
\text { Leadership }\end{array}$} & \multirow{3}{*}{$\begin{array}{c}\text { management } \\
\text { innovation } \\
\text { ability orientation } \\
\text { behavior } \\
\text { orientation } \\
\end{array}$} & 45 & $2231.0^{* * *}$ & 48 & 97.85 & 0.12 & -21.2 \\
\hline & & 25 & $428.1^{* * *}$ & 25 & 94.16 & 0.04 & -18.5 \\
\hline & & 21 & $1785.9^{* * *}$ & 22 & 98.77 & 0.22 & -11.2 \\
\hline \multirow{3}{*}{$\begin{array}{c}\text { Moral } \\
\text { Leadership }\end{array}$} & \multirow{3}{*}{$\begin{array}{c}\text { management } \\
\text { innovation } \\
\text { ability orientation } \\
\text { behavior } \\
\text { orientation } \\
\end{array}$} & 54 & $875.2^{* * *}$ & 57 & 93.49 & 0.04 & 47.2 \\
\hline & & 41 & $601.1^{* * *}$ & 42 & 92.84 & 0.04 & 42.4 \\
\hline & & 15 & $267.8^{* * *}$ & 14 & 94.77 & 0.04 & 21.0 \\
\hline
\end{tabular}

Funnel Plot of Standard Error by Fisher's $Z$

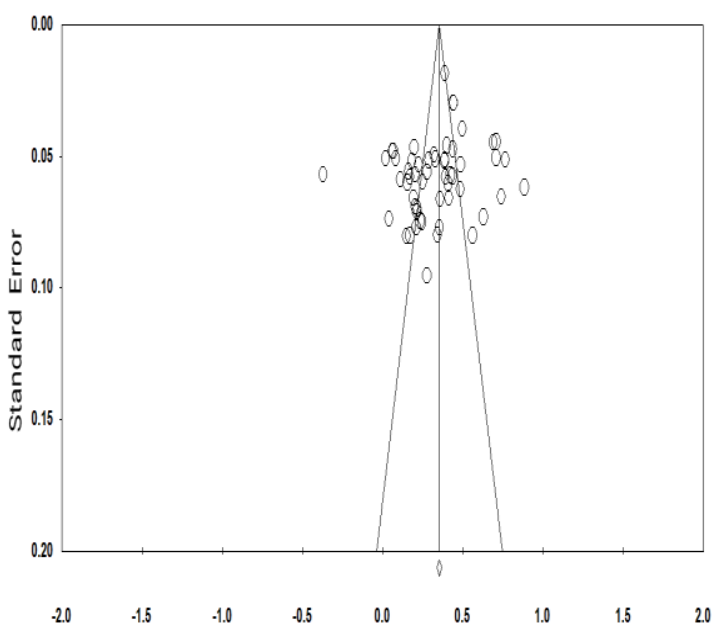

Fig 2. CHART OF BEVENOLENT

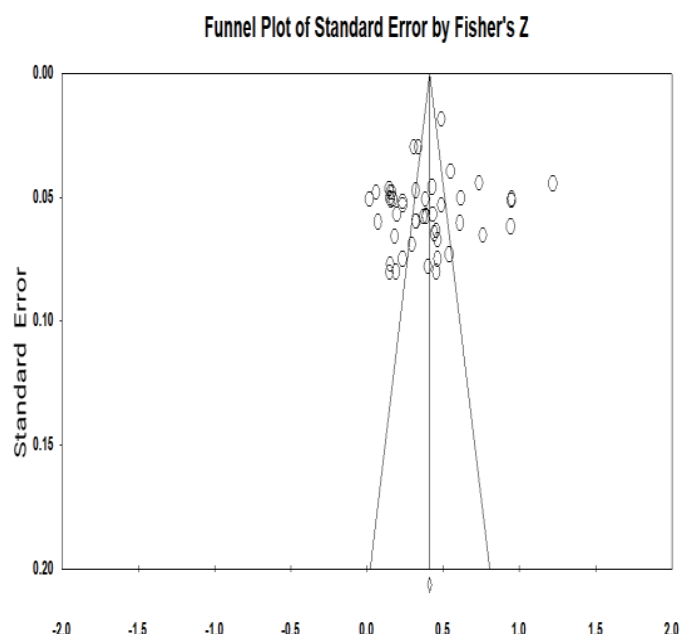

Fig 3. CHART OF AUTHORITARIAN LEADERSHIP LEADERSHIP

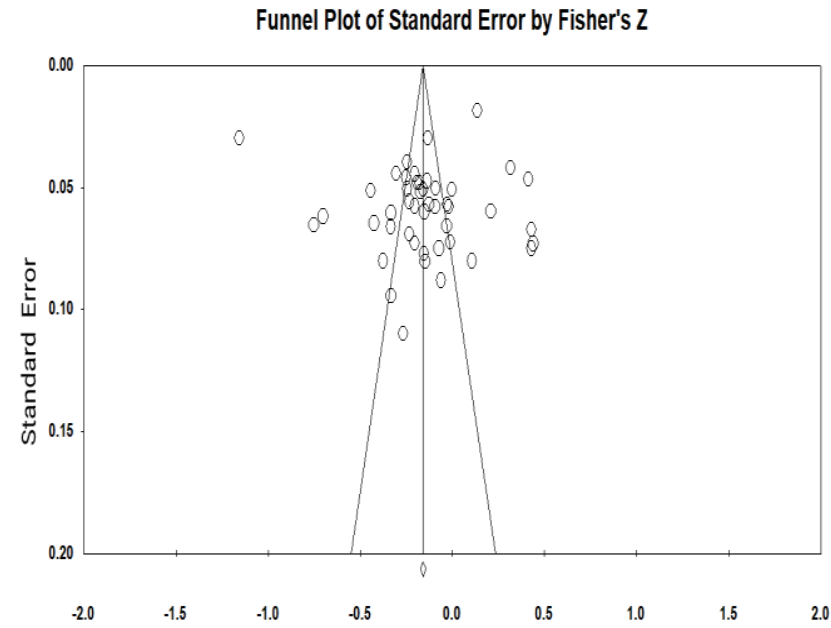

Fig 4. CHART OF MORAL LEADERSHIP

Generally, articles with significant results are more likely to be published, while articles with insignificant results are difficult to publish. Therefore, the effect value of published articles may not represent the true value. Therefore, publication bias should be tested in meta-analysis. In this paper, the coefficient of loss of safety and funnel diagram are used as the test criteria. The coefficient of loss of safety refers to the number of literatures that can make the existing research results not significant. If the coefficient of loss of safety is greater, the possibility of the conclusion being overturned is less. Firstly, the loss of safety factor was used to test the publication bias of this study. The results are shown in Table 1, that is to say, 7981, 6155 and 4578 unpublished 
articles were found in each subject study to make the results of this study not significant [11]. In order to ensure the accuracy of the experimental results, the funnel chart is used as the test standard to test the publication bias of this study. The research results are shown in the funnel diagram. The three types of leadership literature of enterprise management innovation and paternalistic leadership are basically distributed on both sides of the total effect. Therefore, this study exists possibility of publication bias is minimal.

\subsection{Main Effect Test}

Results as shown in Table 2, the correlation between benevolent leadership, authoritarian leadership, moral leadership and overall management innovation is 0.377 , -0.158 and 0.319 , which are significant at the level of 0.001 . Among them, the correlation between authoritative leadership and enterprise overall management innovation was -0.158 , which was significant at the level of 0.01 ; the correlation between moral leadership, benevolent leadership, authoritarian leadership and capability oriented management innovation was 0.344 and 0.344 . The correlation between moral leadership, benevolent leadership, authoritarian leadership and behavior oriented management innovation were $0.245,0.346$ and-0.119 which were significant at the level of 0.001. Among them, benevolent leadership has the strongest correlation with capability oriented management innovation $(\mathrm{r}=0.395, \mathrm{P}<$ $0.001)$, followed by behavior oriented management innovation $(r=0.346, P<0.001)$. In addition, the $Z$ value of authoritarian leadership and behavior oriented management innovation is not significant, that is, we could not determine the effect of authoritarian leadership and behavior oriented management innovation .

\begin{tabular}{|c|c|c|c|c|c|c|}
\hline & $\begin{array}{c}\text { Outcome } \\
\text { variable }\end{array}$ & K & $\mathrm{N}$ & $r /$ slope & $95 \%$ CI & $\mathrm{z}$ \\
\hline ○ & $\begin{array}{l}\text { management } \\
\text { innovation }\end{array}$ & 47 & 20348 & 0.377 & $\begin{array}{l}{[0.435,} \\
0.316]\end{array}$ & $11.231^{\prime \prime}$ \\
\hline
\end{tabular}

\begin{tabular}{|c|c|c|c|c|c|c|}
\hline & $\begin{array}{c}\text { ability } \\
\text { orientation }\end{array}$ & 31 & 11924 & 0.395 & $\begin{array}{l}{[0.478,} \\
0.304]\end{array}$ & $7.959^{* * *}$ \\
\hline & $\begin{array}{c}\text { behavior } \\
\text { orientation }\end{array}$ & 18 & 8424 & 0.346 & $\begin{array}{l}{[0.451,} \\
0.272]\end{array}$ & $8.676^{* * *}$ \\
\hline \multirow{3}{*}{ 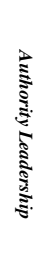 } & $\begin{array}{c}\text { management } \\
\text { innovation }\end{array}$ & 45 & 19166 & -0.158 & $\begin{array}{l}{[-0.061,} \\
-0.253]\end{array}$ & $-3.174^{* * *}$ \\
\hline & $\begin{array}{c}\text { ability } \\
\text { orientation }\end{array}$ & 25 & 9874 & -0.192 & $\begin{array}{l}{[-0.111,} \\
-0.271]\end{array}$ & $-4.607^{*+*}$ \\
\hline & $\begin{array}{c}\text { behavior } \\
\text { orientation }\end{array}$ & 21 & 9292 & -0.119 & $\begin{array}{l}{[0.074,} \\
-0.303]\end{array}$ & $-1.209^{* * *}$ \\
\hline \multirow{3}{*}{ 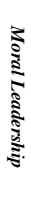 } & $\begin{array}{c}\text { management } \\
\text { innovation }\end{array}$ & 54 & 21900 & 0.319 & $\begin{array}{l}{[0.365,} \\
0.270]\end{array}$ & $12.162^{\circ *}$ \\
\hline & $\begin{array}{c}\text { ability } \\
\text { orientation }\end{array}$ & 41 & 14334 & 0.344 & $\begin{array}{l}{[0.397,} \\
0.288]\end{array}$ & $11.292^{\circ *}$ \\
\hline & $\begin{array}{c}\text { behavior } \\
\text { orientation }\end{array}$ & 15 & 7566 & 0.245 & $\begin{array}{l}{[0.343,} \\
0.141]\end{array}$ & $4.559^{* * * *}$ \\
\hline
\end{tabular}

\subsection{Regulatory Effect Test}

Even if there is a small difference in the effect value, we can judge whether there is a moderating effect in the study by judging whether the $Q$ statistic is significant [12]. The results are shown in Table 3. In Chinese culture context, the correlation between benevolent leadership and overall management innovation is 0.401 , which is significantly higher than that in non-Chinese culture context. The correlation between authoritarian leadership, moral leadership and overall management innovation is -0.158 and 0.323 , respectively The level of innovation plays a moderating role in the relationship between benevolent leadership and the outcome variables, and the correlation between benevolent leadership and team overall management innovation is the strongest. Due to the limitation of sample size, part of the moderating effect of innovation subjects on benevolent leadership and enterprise management innovation cannot be evaluated. The analysis of authoritarian leadership and moral leadership is the same as above.

Table3. THE MODERATING EFFECT OF RELATED VARIABLES

\begin{tabular}{|c|c|c|c|c|c|c|c|}
\hline $\begin{array}{c}\text { Antecedent } \\
\text { variable }\end{array}$ & Adjustment variable & $\mathbf{K}$ & $\mathbf{N}$ & r/slope & $95 \%$ CI & $\mathbf{Z}$ & Heterogeneity Q \\
\hline & $\begin{array}{l}\text { Cultural situations } \\
\text { China } \\
\text { non-China }\end{array}$ & $\begin{array}{c}42 \\
5\end{array}$ & $\begin{array}{c}18345 \\
2003\end{array}$ & $\begin{array}{l}0.401 \\
0.153\end{array}$ & $\begin{array}{l}{[0.339,0.459]} \\
{[0.030,0.271]}\end{array}$ & $\begin{array}{l}11.681^{* * *} \\
2.443^{*}\end{array}$ & $\begin{array}{c}1014.921^{* * * *} \\
31.674^{* * *}\end{array}$ \\
\hline Leadership & $\begin{array}{c}\text { Innovation level } \\
\text { individuals } \\
\text { teams } \\
\text { organizations }\end{array}$ & $\begin{array}{c}33 \\
7 \\
7\end{array}$ & $\begin{array}{l}14656 \\
3177 \\
2515\end{array}$ & $\begin{array}{l}0.331 \\
0.579 \\
0.373\end{array}$ & $\begin{array}{l}{[0.276,0.384]} \\
{[0.343,0.746]} \\
{[0.321,0.422]}\end{array}$ & $\begin{array}{r}11.027^{* * * *} \\
4.268^{* * * *} \\
13.110^{* * *}\end{array}$ & $\begin{array}{c}450.790^{* * *} \\
449.775^{* * *} \\
14.655^{* *}\end{array}$ \\
\hline & $\begin{array}{l}\text { Cultural situation } \\
\text { China } \\
\text { Non-China }\end{array}$ & $\begin{array}{c}43 \\
3\end{array}$ & $\begin{array}{c}18271 \\
895\end{array}$ & $\begin{array}{l}-0.158 \\
-0.148\end{array}$ & $\begin{array}{l}{[-0.257,-0.055]} \\
{[-0.303,-0.015]}\end{array}$ & $\begin{array}{l}-3.005^{* *} \\
-1.779\end{array}$ & $\begin{array}{c}2217.919^{* * *} \\
10.916^{* *}\end{array}$ \\
\hline $\begin{array}{c}\text { Authoritarian } \\
\text { Leadership }\end{array}$ & $\begin{array}{c}\text { Innovation level } \\
\text { individuals } \\
\text { teams } \\
\text { organizations }\end{array}$ & $\begin{array}{c}32 \\
6 \\
7\end{array}$ & $\begin{array}{l}13755 \\
2896 \\
2515\end{array}$ & $\begin{array}{l}-0.170 \\
-0.169 \\
-0.099\end{array}$ & $\begin{array}{r}{[-0.293,-0.042]} \\
{[-0.382,0.061]} \\
{[-0.241,0.043]}\end{array}$ & $\begin{array}{l}-2.590^{*} \\
-1.446 \\
-1.319\end{array}$ & $\begin{array}{l}1935.464^{* * *} \\
199.532^{* * *} \\
94.642^{* * *}\end{array}$ \\
\hline $\begin{array}{c}\text { Moral } \\
\text { Leadership }\end{array}$ & $\begin{array}{l}\text { Cultural situation } \\
\text { China } \\
\text { Non-China }\end{array}$ & $\begin{array}{l}44 \\
10\end{array}$ & $\begin{array}{c}18607 \\
3293\end{array}$ & $\begin{array}{l}0.323 \\
0.295\end{array}$ & $\begin{array}{l}{[0.270,0.375]} \\
{[0.171,0.409]}\end{array}$ & $\begin{array}{l}11.199^{* * *} \\
4.546^{* * *}\end{array}$ & $\begin{array}{l}950.304^{* * *} \\
225.784^{* * *}\end{array}$ \\
\hline
\end{tabular}




individuals
teams
organizations

teams
organizations

36
10
9

14947
3724
3229

0.269
0.440
0371

$[0.210,0.326]$
$[0.316,0.548]$
$[0.305,0.434]$

$[0.316,0.548]$

$\begin{array}{cc}8.683^{* * *} & 518.620^{* * *} \\ 6.397^{* * *} & 174.996^{* * *} \\ 10.158^{* * *} & 40.749^{* * *}\end{array}$

\section{Discussion}

This study uses meta-analysis technology to study the effect of paternalistic leadership on enterprise management innovation. The results show that benevolent leadership, moral leadership and overall management innovation, ability oriented management innovation, behavior oriented management innovation have significant positive correlation, while authoritarian leadership has significant negative correlation with management innovation and focus management innovation. The results of meta-analysis are consistent with the existing research data.

\subsection{The relationship between paternalistic leadership and enterprise management innovation has a certain impact}

In paternalistic leadership, benevolent leadership, moral leadership and authoritarian leadership have a significant impact on multi focus enterprise management innovation, and play a significant impact on the construction of high-quality innovative enterprises [13]. Therefore, paternalistic leaders can create a good atmosphere for innovation for enterprises, not only in interpersonal communication and daily work to reflect a high level of moral quality and Employee care, but also to avoid strict constraints on employees [14], Leadership style is an important situational factor to predict innovations.

Authoritarian leadership, moral leadership and benevolent leadership have significant impact on enterprise management innovation [15]. According to the social exchange theory [16] and the principle of reciprocity, when a leader takes a positive leadership behavior, his subordinates will feel solicitude and fair treatment, and the subordinates will take the initiative to form a stable social exchange relationship with their own leaders, and in order to repay the appreciation of leaders, employees will take more active work behavior [17]. Under authoritarian leadership, leaders will pay more attention to employees' physical education It show absolute control and domination, never allow employees to make mistakes, and emphasizes the absolute personal authority of leaders. Authoritarian leadership is an imperative leadership behavior, which emphasizes the absolute obedience and control of subordinates, and requires subordinates to strictly abide by rules and regulations, and keep a certain distance from them, Take absolute command of leadership, so as to cultivate and edify employees "willing to innovate, dare to innovate" corporate culture, is also an important factor to form a good enterprise innovation atmosphere.

\subsection{The influence of moderating variables on the relationship between paternalistic leadership and enterprise management innovation}

\subsubsection{Innovation level:}

Due to the different levels of enterprise management innovation implementation, in order to maximize their own interests and create higher enterprise value, employees will choose the best focus behavior according to different scenarios and leaders. Research shows that moral leadership, benevolent leadership and behavior oriented management innovation are significantly positively correlated, authoritarian leadership and ability, behavior oriented management There is a significant negative correlation between innovation and innovation. In the process of enterprise management innovation, employees are the owners of innovation ability and innovation behavior. In the face of tough and commanding authoritarian leaders, even if they have outstanding innovation ability, employees will choose to protect themselves, only complete the tasks assigned by leaders, and lack of intrinsic motivation and innovation enthusiasm to produce innovative behavior.

\subsubsection{Cross cultural situation:}

The cross-cultural situation plays a moderating role in the relationship between paternalistic leadership and multi focus management innovation. In the Chinese context, paternalistic leadership has a stronger impact on overall management innovation, which is influenced by the strong traditional Chinese Confucian culture and family concept. Enterprise employees generally recognize the leadership style of "set an example", "set an example for the world" and "show morality as a person"[18] . Industry leaders generally agree with the working attitude of "offering a peach for a favor", "reciprocity" and "mutual benefit". Benevolent leadership and moral leadership have similar characteristics with the above-mentioned style and characteristics. When leaders and employees show the above behavior characteristics in actual work, both employees and leaders will be positively affected by each other. Leaders will choose to treat employees leniently. As a reward and result, employees will treat leaders through innovation. However, in the western organizational context, enterprise management emphasizes more on strict hierarchical system and ignores the concern for human nature of employees. Leaders show low benevolence and virtue, and have high authoritarian characteristics. Employees naturally show low innovation in this low humanistic organizational environment. 


\section{Eficiencies and future development}

Due to the limitation of sample size, the research failed to analyze some moderating variables, such as authoritarian leadership and moral leadership, which affected the comprehensiveness of the study to a certain extent. On the other hand, due to the slow development of paternalistic leadership research in the west, the sample size of this study on non-Chinese context is relatively small, which will affect the moderating effect of cross-cultural situation to some extent. Secondly, the sample size of unpublished papers is insufficient. Future research can enrich the sample size of literature, and at the same time, it will bring parents with Chinese characteristics. We conduct a meta-analysis and comparative study on the influence of leadership style with Western characteristics on enterprise management innovation. In the future research, we can introduce more abundant regulatory variables, such as region, enterprise organizational structure.

\section{References}

1. Anderson N, Potocnik K, Zhou Jing. Innovation and creativity in organizations: A state of the science review ,prospective commentary, and guiding framework . J. Journal of Management,2014,40(5):1297-1333.

2. Shi Guanfeng, Han Hongwen. Influence of leadership behavior on Team Creativity: a comparative analysis .J. Science and technology management research, 2014,34 (19): 102-108.

3. Chang Tao, Liu Zhiqiang, Jing Baofeng. Paternalistic leadership and team creativity: a new discovery based on the ternary theory. J. Research and development management (phase 1): 62-72.

4. W.Yating and T.Chaoying, Paternalistic Leadership and Innovative Behavior: Psychological Empowerment as a Mediator. J.Journal of Management \& Organization, 2017, 8(2).

5. Lin Chunpei, Zhuang Bochao. The influence of paternalistic leadership on Management Innovation: an integrated model. J. Scientific research, 2014 (04): 144-152.

6. Wang Zhen, Liu jiejiao. Research on organizational innovation performance: Based on Chinese leadership .J. Modern management science, 2017 (12): 12-18.

7. Farh J L, Cheng B S. A cultural analysis of paternalistic leadership in Chinese organizations. M. Tsui A S, Weldon E. Management and organizations in the Chinese context. London: Macmillan, 2000: 84127.

8. Wang Li, Cai Yonghong. Paternalistic leadership and teachers' teaching innovation performance: the mediating role of trust and autonomous motivation . J. Educational research and experiment, 2016, (002): 41-46.
9. Lin Ziting, Zheng Boxun, Zhou Lifang. Review and Prospect of Paternalistic Leadership: Rethinking . J. Management Quarterly, 2017 (4): 1-32.

10. Higgins J . P, Thompson S . G . Quantifying Heterogeneity in Meta-Analysis. J. Statistics in Medicine, 2002, 21(11):1539-1558.

11. R osenthal $R$. The'File Drawer Problem'and Tolerance for Null R esults. J. Psychological Bulletin, 1979, 86( 3) :638-641.

12. Koslowsky M , Sagie A. On the Efficacy of Credibility Intervals As Indicators of Moderator Effects in Meta-Analytic R esearch. J. Journal of Organizational Behavior, 1993, 14(7):695-699.

13. Zhang Zhengang, Yu chuanpeng, Cui Tingting. The influence of paternalistic leadership and psychological empowerment on enterprise management innovation. J. Science and technology management research, 2015,35 (03): 203-208.

14. Chen Yanyan, Zhao Yongle, sun Rui. The influence of paternalistic leadership style on enterprise innovation performance: Based on the mediating effect of organizational emotional ability. J. Zhejiang Social Sciences, 2019 (05): 33-39.

15. $\mathrm{Li} \mathrm{Yi}, \mathrm{Wu}$ Jianmei. The influence of error management climate on employees' innovative behavior: the moderating role of paternalistic leadership . J. Science and technology management research, 2019, 39 (03): 156-165.

16. Shi Guanfeng, Li Kun. Authoritarian leadership and benevolent leadership influence team creativity: a mediating interaction model test . J.. Journal of Guizhou University of Finance and economics, 2014 (5) .

17. Meng Yishuang, Hu Shan. Research on the influence of active leadership on hotel employees' innovative behavior. J. Contemporary economy, 2017 (21): 148-151.

18. Wang Shuanglong, Zhou Haihua. Mechanism of paternalistic leadership on individual innovation behavior. J. Soft science, 2013, 27 (12): 53-57. 